Science, Technology and Development 34 (4): 215-220, 2015

ISSN 0254-6418 / DOI: 10.3923/std.2015.215.220

(C) 2015 Pakistan Council for Science and Technology

\title{
An Insight into Phytoremediation of Heavy Metals from Soil Assisted by Ancient Fungi from Glomeromycota-Arbuscular Mycorrhizal Fungi
}

\author{
${ }^{1}$ Muhammad Shakeel and ${ }^{2}$ Tabassum Yaseen \\ ${ }^{1}$ Department of Biotechnology, Bacha Khan University, Charsadda, Khyber Pakhtunkhwa, Pakistan \\ ${ }^{2}$ Department of Botany, Bacha Khan University, Charsadda, Khyber Pakhtunkhwa, Pakistan
}

\begin{abstract}
Arbuscular Mycorrhizal (AM) fungi form mutualistic relationship with plant roots which improves plant growth and confers tolerance against many types of stresses, including heavy metals tolerance. AM fungi allows enhanced-growth of plants, grown on heavy metals contaminated soil. They have been involved in regulating the uptake of heavy metals from root to shoot exploiting the potential of membrane transporters. These fungi either increase the uptake of heavy metals from root to shoot (phytoextraction) or stop their spreading in soil, using different mechanisms including accumulation of toxic metals in hyphae, chelation of metals with substances released by fungal hyphae or adhering these metals with roots surface or chitin of fungal cell wall. The latter approach, used by AM fungi, is known as phytostabilization, which stops the dissemination and leakage of heavy metals in the soil keeping the ecosystem in equilibrium and makes it suitable for optimum plant growth. Apart from this, spores isolated from the heavy metals contaminated soil have shown enhanced resistance to presence of heavy metals than non-contaminated soil. Such acquired resistance or tolerance is not durable as it has not being developed as a result of genetic changes but due to phenotypic plasticity of spores. Such resistance may be lost if these spores are being grown on non-heavy-metals-contaminated soil. For efficient phytoremediation, the potential of plant transporters in response to AM fungi should be exploited. It would be ideal to see if these membrane transporters genes could be expressed by AM fungal promoters for enhanced metals remediation and restoring the damaged ecosystem.
\end{abstract}

Key words: Arbuscular mycorrhizal fungi, heavy metal tolerance, acquired resistance, phytoremediation

\section{INTRODUCTION}

The presence of heavy metals in soil is harmful to plants, humans, environment (Bibi et al., 2006) and microbes as they may affect microbial colonization (Lingua et al., 2008) and their community composition (Sobolev and Begonia, 2008). Most of the land plants take up nutrients from soil (Langille and Maclean, 1976) necessary for its growth and productivity. Some plant species have been reported to take up heavy metals (Cu, Zn, Pb, Cr, Cd, Ag, Se, Hg) (Baker and Brooks, 1989) from the soil contaminated from different sources such as artificial/synthetic chemical fertilizers, insecticides, pesticides, industrial wastes and vehicles emission (Qian et al., 1999).

Plants show variable responses to the presence and uptake of heavy metals in soil. Heavy metals can be accumulated by some plant species to certain level (Baker and Brooks, 1989) beyond which drastic effects on growth and productivity can arise. Some plant species have been reported to be metal sensitive (Huang et al., 2000) and show reduced growth and productivity with their presence while others are tolerant and show enhanced yield (Rabie, 2005) and productivity. Plant's tolerance towards metals uptake can be analysed from root and shoot growth, water content and various physiological, biochemical and enzymatic activities of plant cell. Such plants characteristics can be used as markers for selecting heavy metals tolerant plants (Rabie, 2005).

Phytoremediation is the most efficient and economical approach for the remediation of heavy metals from the soil as other remediation methods used are expensive and time demanding (Belliturk et al., 2015; Fitz and Wenzel, 2002). It is particularly being useful for remediation of non-volatile heavy metals which cannot be remediated from soil using any other method (Khan et al., 2000). Phytoremediation represents those mechanisms (Paz-Ferreiro et al., 2014), which can lead to reduced concentration of heavy metals, complete elimination from soil or its decomposition into environmentally and ecologically harmless components (Denton, 2007; Lambi et al., 2001). For successful progression of phytoremediation, different approaches can be used,

Corresponding Author: Muhammad Shakeel, Department of Biotechnology, Bacha Khan University, Charsadda, Khyber Pakhtunkhwa, Pakistan 
including selection of tolerant plant species and exploiting soil and plant promoting microorganisms (Burd et al., 2000; Glick, 2003; Newman and Reynolds, 2005).

Aims and significance of the current review: This study is aimed to highlight the main limitations in previous methods of phytoremediation and draw people's attention towards AM fungi, which can take up toxic metals from the deep soil using extended and dense network of hyphae, where plant roots cannot reach.

As the exact molecular mechanism by which AM fungi detoxify toxic metals is unknown, this study intensifies the need to unravel the mechanism for their best utilization in phytoremediation studies. It also stresses on the selection of suitable plant species and fungal strains for efficient phytoremediation based on previous published reports. To my knowledge, it is the first report evaluating the classical and AM fungal based heavy metal remediation methods, stresses to explore the fungal based detoxification mechanism and pointing towards the potential area in AM fungi which can be exploited in future bioremediation programmes.

Arbuscular mycorrhizal fungi and phytoremediation: Among the microbes, symbiotic fungi, such as, arbuscular mycorrhizal (AM) fungi, has widely been studied in relationship to phytoremediation (Entry et al., 2002; Meier et al., 2012). Arbuscular mycorrhiza is a mutualistic relationship between plants roots (Sieverding, 1990) and fungi, in which the plant provides the fungus with carbohydrates and receives nutrients (Nitrogen and Phosphorus in particular) in return (Nadian et al., 1997). Numerous studies have reported that AM fungi can grow in soil largely contaminated with heavy metals (Shetty et al., 1994) indicating they have fast adaptation (Joner and Leyval, 1997) and evolved the mechanism to accumulate or tolerate these metals. Extensive network of hyphae and mycelium is one of the approaches used by these fungi for the uptake of heavy metals from deep soil. As different strains of AM fungi respond differently to remediation of heavy metals, therefore, concentration of these toxic metals in plants species varies (Heggo et al., 1990; Joner and Leyval, 1997) in response to different fungal strains. Considering this enormous variability in metals uptake, efficient fungal strains having greater metals uptake potential should be used for phytoremediation as utilization of other strains will be time consuming, less efficient and expensive.

Among the available remediation methods (physical and chemical), phytoremediation, involving higher plants (Pilon-Smits, 2005), is getting more attention as these metals cannot be converted chemically to less toxic form and need to be physically removed (Kroopnick, 1994) from the soil or keep them in a proportion that does not affect the plant growth. This method of remediating toxic metals from the soil is less expensive, safe and environmentally friendly (Thewys et al., 2010). Increased growth and cupper uptake from root to shoot of E. splendens have been observed at certain concentration of Cupper. This increase in shoot dry matter and cupper uptake was larger in the AM inoculated plants than non AM inoculated plants which clearly shows the role of AM fungi in alleviating heavy metals from soil through plants (Wang et al., 2005). Similar results were obtained in another experiment conducted by these authors (Wang et al., 2005; Wang et al., 2007).

Microbial inoculation not only increased shoot dry matter but also the uptake of $\mathrm{Cu}, \mathrm{Zn}, \mathrm{Pb}$ and $\mathrm{Cd}$ by shoot, leading to increased phytoextraction of heavy metals. Excessive presence of $\mathrm{Pb}$ and $\mathrm{Cd}$ in the soil results in reduced growth and production of pot marigold. After being inoculated with arbuscular mycorrhizal fungi, it not only improved the growth and yield of the pot marigold (Calendula officinalis L.) but enhanced the phytoextraction of these heavy metals to large extent. This study also reported that Cd has more harmful effects on plant growth than $\mathrm{Pb}$ which should be prioritised in future phytoremediation studies (Tabrizi et al., 2015). Similarly, presence of nickel in soil has been reported to have adverse effects on growth of tall fescue (Festuca arundinacea L.) and contents of photosynthetic pigments. Inoculation of these plants with AM fungi ( $R$. mosseae) reduced nickel uptake from roots to shoots reflecting the importance of these fungi in relieving nickel stress (Shabani et al., 2016). Adverse effects of high concentration of zinc on the plant growth and other parameters, such as, putrescine profile in the leaves of poplar, have been reduced in plants colonized by Rhizophagus mosseae. Some studies have shown that high Zinc concentration in the soil sometimes inhibits AM fungal colonization (Lingua et al., 2008) of the host plants which results in reduced spore formation (Del Val et al., 1999). The reduced uptake of uranium and thorium in shoot has been reported in AM colonized plants than non-AM colonized plants, which reflects the role of these fungi in phytostabilization of uranium and thorium (Roos and Jakobsen, 2008).

A study conducted for evaluating the efficiency of heavy metal uptake $(\mathrm{Zn}, \mathrm{Cu}, \mathrm{Pb}, \mathrm{Cd})$ by $\mathrm{AM}$ fungal inoculation and EDTA treatment has shown the highest uptake of all metals except $\mathrm{Pb}$ for AM fungal inoculated crops and high $\mathrm{Pb}$ uptake for EDTA treated plants. It is worth mentioning that $\mathrm{Pb}$ uptake by EDTA treated crops was higher than AM fungal inoculated plants (Liang et al., 2009; Usman and Mohamed, 2009). 
How AM fungi detoxify heavy metals?: AM fungi are not only playing a remarkable role in ensuring good vegetation in the contaminated soil but also participate in detoxification of heavy metals presumably by intracellular processes (Blaudez et al., 2000; Jentschke and Godbold, 2000). The exact mechanism by which heavy metals can be detoxified by AM fungi is not exactly known. Metallothioneins are believed to be involved in detoxification of toxic metals as they may either bind to heavy metals or act as antioxidant in the detoxification process. Metallothioneins are basically small proteins, produced by multi-gene families of plants and playing an important role in metals based stress (Akashi et al., 2004; Cobbett and Goldsbrough, 2002). The information regarding involvement of metallothioneins in detoxification of metals arose from gene expression studies of metallothioneins and other studies performed on poplar plants (Balestrazzi et al., 2009; Castiglione et al., 2007).

Some fungal types obtained from zinc wastes have been reported to reduce the metal uptake by the plant in order to stop these metals from entering into food chains and control the resulting diseases (Turnau et al., 2006). It can be accomplished by numerous membrane transporters which have been shown to reduce heavy metals uptake in both plants and microbes (Clemens, 2001). Many transporters have been reported in higher plants responsible for transport of heavy metals from the contaminated soil. It would be more interesting to see if these transporter genes could be expressed by AM fungal inducible promoters for efficient phytoremediation. In such situation, heavy metals from the soil will be removed after being absorbed in the fungal hyphae or any other cellular structure (Hall and Williams, 2003).

AM fungi either remediate these metals by increasing root to shoot uptake (phytoextraction) or restrained them in the soil (phytostabilization). The success of soil treatment with AM fungi depends on plant and fungal species and on the nature of target heavy metals itself. It also depends on the soil physical conditions such as temperature, $\mathrm{pH}$ and humidity (Gaur and Adholeya, 2004; Khan, 2005). Arbuscular mycorrhiza (i.e., Rhizophagus mosseae), showing resistance to cadmium, has been reported to be involved in the uptake and passage of cadmium from the heavy metals contaminated soil (Joner and Leyval, 1997). Cu was found to have been absorbed in the hyphae of Rhizophagus isolates (Gonzalez-Chavez et al., 2002) and plant roots in non-toxic form (Tonin et al., 2001).

Hyphae and mycelium can accumulate large amounts of heavy metals reaching up to $20 \%$ plant dry mass (Tobin et al., 1984). In some AM fungal strains, substances secreted from these hyphae have been shown to be involved in chelation of heavy metals (Gaur and Adholeya, 2004). Similarly, there are also some AM fungal strains that are resistant to aluminium as increased level of aluminium in the soil can lead to reduced concentration of Ca and Mg (Cumming and Ning, 2003) in the plant cell. Spores produced by AM fungi in the contaminated soil have shown increased tolerance against heavy metals stress than spores collected from non-contaminated soil. Such spores-derived resistance can be lost after growing these fungal spores in non-contaminated soil as the observed resistance is due to spore's phenotypic manipulability not genetic alterations (Shalaby, 2003; Gaur and Adholeya, 2004). Such type of resistance developed in response to adverse climatic/soil conditions is not durable as it is not controlled by genetic material. It may remain tolerant as long as it is present in the contaminated soil.

Pawlowska and Charvat (2004) demonstrated that Rhizophagus irregularis conferred more tolerance against heavy metals than Rhizophagus etunicatum. Plant roots coupled with dense network of long hyphae can take up heavy metals from about 47 fold (Smith and Read, 1997) more soil depth than plant roots alone which highlights the role of AM fungi in phytoremediation of toxic metals. In contrast to phytoremediation, phytostabilization stop spreading and leakage of the metals in the soil. In this method, heavy metals may adsorb on plant root surfaces or chitin of fungal cell wall, chelate with substances secreted by these fungi and/or accumulated inside roots without transferring it to shoot or leaking into deep soil (Wong et al., 2003; Joner et al., 2000). AM fungi with extended network of hyphae are involved in non-spreading of heavy metals in deep soil where plant roots cannot penetrate and accelerate the process of phytostabilization (Gaur and Adholeya, 2004).

\section{DISCUSSION}

Heavy metals found in the soil are harmful to plants, humans and animals. These metals have been accumulated in soil as a result of mining, fertilizers and pesticides applications, industrial effluents or wastes, vehicles smokes and other human activities. The soil needs to be cleaned up from these contaminants as they are not only affecting plant growth but also humans, after entering into food chain and disrupting life. Different strategies have been used to clean soil from heavy metals but they are normally expensive, time consuming and not very efficient in taking off all the metals. Phytoremediation offers the possibility for taking up the toxic metals from the soil especially the non-volatile metals and those heavily mixed with soil. Selection of suitable plants is the key for successful phytoremediation 
as different plant species respond differently to remediation of heavy metals from the soil. One drawback of phytoremediation is that roots cannot reach into deep soil containing heavy metals.

Arbuscular mycorrhizal fungi with extended network of hyphae overcome this constraint in phytoremediation as these hyphae can reach deep into soil and play an essential role in heavy metals uptake in association with plant roots. In some cases, they enhance metal uptake from the soil whereas in others; they allow limited uptake of metals keeping them in an amount in soil which does not adversely affect plant growth and yield. It means that the concentration of these toxic metals in plant species varies in response to different AM fungal strains. Presence of heavy metals in soil can reduce plants colonization by some AM fungal strains but other fungal strains have been reported to be tolerant to these metals and perform well in soil heavily contaminated with heavy metals. Fungal spores isolated from the heavy metal contaminated soil have shown resistance to heavy metals than spores isolated from non-metal contaminated soil. This type of spores-based resistance is not robust as it has not been developed as a result of alternations in genetic material (DNA/RNA) but merely due to plasticity of spores. The spores based resistance may be lost in the next generation if grown in the non-heavy metals contaminated soil.

In phytoextraction, toxic metals are remediated from the soil by enhancing root to shoot uptake which are finally being lost after crop/plant harvesting. In case of phytostabilization, these contaminants may adhere to roots or fungal cell wall or get accumulated in plant roots without being transferred to shoots. These contaminants may chelate with substances released by fungal hyphae which inhibit their leakage or spreading in the soil and keep them in a balanced form. Arbuscular mycorrhizal fungi with enlarged and extended network of hyphae can take up toxic metals from the deep soil which is beyond the plant roots access and is playing an important role in phytostabilization and phytoextraction. Another potential area which can be exploited in remediation of heavy metals is membrane transporters which are involved in regulation of heavy metals from root to shoot. It will be fascinating to see if these transporter genes could be expressed using AM fungal promoters for more efficient remediation of metals.

\section{CONCLUSION}

Arbuscular mycorrhizal fungi play a vital role in the remediation of heavy metals from the heavy metals contaminated soil, using different mechanisms, including, detoxification of toxic metals and chelation of metals with AM fungal secreted substances. AM fungi with dense network of hyphae can take up toxic metals from the soil zone, where plant roots cannot reach. AMF-mediated phytoremediation of heavy metals either increase heavy metals uptake from roots to shoot or stop its dissemination in soil. AM fungal spores isolated from the heavy metals contaminated soil have shown enhanced resistance towards heavy metals stress than spores isolated from the non-contaminated soil. Different strains of AM fungi may respond differently to heavy metals uptake, therefore, screening and identification of efficient fungal strains form the basis of successful bioremediation programme. Plasma membrane transporter is one of the potential areas which need to be explored in association with AM fungal promoters for improved bioremediation of heavy metals from soil.

\section{REFERENCES}

Akashi, K., N. Nishimura, Y. Ishida and A. Yokota, 2004. Potent hydroxyl radical-scavenging activity of drought-induced type-2 metallothionein in wild watermelon. Biochem. Biophys. Res. Commun., 323: 72-78.

Baker, A.J.M. and R.R. Brooks, 1989. Terrestrial higher plants which hyper accumulate metallic elements-a review of their distribution, ecology and phytochemistry. Biorecovery, 1: 81-126.

Balestrazzi, A., S. Botti, S. Zelasco, S. Biondi and C. Franchin et al., 2009. Expression of the PsMT $T_{A 1}$ gene in white poplar engineered with the MAT system is associated with heavy metal tolerance and protection against 8-hydroxy-2'-deoxyguanosine mediated-DNA damage. Plant Cell Rep., 28: 1179-1192.

Belliturk, K., P. Shrestha and J.H. Gorres, 2015. The importance of phytoremediation of heavy metal contaminated soil using vermicompost for sustainable agriculture. J. Rice Res., Vol. 3. 10.4172/2375-4338.1000e114

Bibi, M., M. Hussain, M.S. Qureshi, S. Kousar and S. Ajaz, 2006. Heavy metal and nutrient ion accumulation by two black gram cultivars treated with copper and lead. J. Plant Nutr., 29: 913-920.

Blaudez, D., B. Botton and M. Chalot, 2000. Cadmium uptake and subcellular compartmentation in the ectomycorrhizal fungus Paxillus involutus. Microbiology, 146: 1109-1117.

Burd, G.I., D.G. Dixon and B.R. Glick, 2000. Plant growth-promoting bacteria that decrease heavy metal toxicity in plants. Can. J. Microbiol., 46: 237-245. 
Castiglione, S., C. Franchin, T. Fossati, G. Lingua, P. Torrigiani and S. Biondi, 2007. High zinc concentrations reduce rooting capacity and alter metallothionein gene expression in white poplar (Populus alba L. cV. Villafranca). Chemosphere, 67: 1117-1126.

Clemens, S., 2001. Molecular mechanisms of plant metal tolerance and homeostasis. Planta, 212: 475-486.

Cobbett, C. and P. Goldsbrough, 2002. Phytochelatins and metallothioneins: Roles in heavy metal detoxification and homeostasis. Annu. Rev. Plant Biol., 53: 159-182.

Cumming, J.R. and J. Ning, 2003. Arbuscular mycorrhizal fungi enhance aluminium resistance of broomsedge (Andropogon virginicus L.). J. Exp. Bot., 54: 1447-1459.

Del Val, C., J.M. Barea and C. Azcon-Aguilar, 1999. Assessing the tolerance to heavy metals of arbuscular mycorrhizal fungi isolated from sewage sludgecontaminated soils. Applied Soil Ecol., 11: 261-269.

Denton, B.P., 2007. Advances in phytoremediation of heavy metals using plant growth promoting bacteria and fungi. MMG 445 Basic Biotechnol. eJ., 3: 1-5.

Entry, J.A., P.T. Rygiewicz, L.S. Watrud and P.K. Donnelly, 2002. Influence of adverse soil conditions on the formation and function of Arbuscular mycorrhizas. Adv. Environ. Res., 7: 123-138.

Fitz, W.J. and W.W. Wenzel, 2002. Arsenic transformations in the soil-rhizosphere-plant system: Fundamentals and potential application to phytoremediation. J. Biotechnol., 99: 259-278.

Gaur, A. and A. Adholeya, 2004. Prospects of arbuscular mycorrhizal fungi in phytoremediation of heavy metal contaminated soils. Curr. Sci., 86: 528-534.

Glick, B.R., 2003. Phytoremediation: Synergistic use of plants and bacteria to clean up the environment. Biotechnol. Adv., 21: 383-393.

Gonzalez-Chavez, C.D., J. D'Haen, J. Vangronsveld and J.C. Dodd, 2002. Copper sorption and accumulation by the extraradical mycelium of different Glomus spp. (arbuscular mycorrhizal fungi) isolated from the same polluted soil. Plant Soil, 240: 287-297.

Hall, J.L. and L.E. Williams, 2003. Transition metal transporters in plants. J. Exp. Bot., 54: 2601-2613.

Heggo, A., A. Angle and R.L. Chaney, 1990. Effects of vesicular-arbuscular mycorrhizal fungi on heavy metal uptake by soybeans. Soil Biol. Biochem., 22: 865-869.
Huang, X.D., B.R. Glick and B.M. Greenberg, 2000. Combining Remediation Techniques Increases Kinetics for Removal of Persistent Organic Contaminants from Soil. In: Environmental Toxicology and Risk Assessment: Science, Policy and Standardization-Implications for Environmental Decisions, Greenberg, B.M., R.N. Hull, M.H. Roberts Jr. and R.W. Gensemer (Eds.). Vol. 10, ASTM International, West Conshohocken, PA., USA., ISBN-13: 9780803128866, pp: 271-282.

Jentschke, G. and D.L. Godbold, 2000. Metal toxicity and ectomycorrhizas. Physiologia Plantarum, 109: 107-116.

Joner, E.J. and C. Leyval, 1997. Uptake of ${ }^{109} \mathrm{Cd}$ by roots and hyphae of a Glomus mosseae/Trifolium subterraneum mycorrhiza from soil amended with high and low concentrations of cadmium. New Phytol., 135: 353-360.

Joner, E.J., R. Briones and C. Leyval, 2000. Metal-binding capacity of arbuscular mycorrhizal mycelium. Plant Soil, 226: 227-234.

Khan, A.G., 2005. Role of soil microbes in the rhizospheres of plants growing on trace metal contaminated soils in phytoremediation. J. Trace Elements Med. Biol., 18: 355-364.

Khan, A.G., C. Kuek, T.M. Chaudhry, C.S. Khoo and W.J. Hayes, 2000. Role of plants, mycorrhizae and phytochelators in heavy metal contaminated land remediation. Chemosphere, 41: 197-207.

Kroopnick, P.M., 1994. Vapor Abatement Cost Analysis Methodology for Calculating Life-Cycle Costs for Hydrocarbon Vapor Extracted during Soil Venting. In: Remediation of Hazardous Waste Contaminated Soils, Wise, D.L. and D.J. Trantolo (Eds.). Chapter 32, Marcel Dekker Inc., New York, USA., ISBN-13: 9780824791605, pp: 779-790.

Lambi, E., F.J. Zhao, S.J. Dunham and S.P. McGrath, 2001. Phytoremediation of heavy metal-contaminated soils. J. Environ. Qual., 30: 1919-1926.

Langille, W.M. and K.S. MacLean, 1976. Some essential nutrient elements in forest plants as related to species, plant part, season and location. Plant Soil, 45: 17-26.

Liang, C.C., T. Li, Y.P. Xiao, M.J. Liu, H.B. Zhang and Z.W. Zhao, 2009. Effects of inoculation with arbuscular mycorrhizal fungi on maize grown in multi-metal contaminated soils. Int. J. Phytorem., 11: 692-703.

Lingua, G., C. Franchin, V. Todeschini, S. Castiglione and S. Biondi et al., 2008. Arbuscular mycorrhizal fungi differentially affect the response to high zinc concentrations of two registered poplar clones. Environ. Pollut., 153: 137-147. 
Meier, S., F. Borie, N. Bolan and P. Cornejo, 2012. Phytoremediation of metal-polluted soils by Arbuscular mycorrhizal fungi. Crit. Rev. Environ. Sci. Technol., 42: 741-775.

Nadian, H., S.E. Smith, A.M. Alston and R.S. Murray, 1997. Effects of soil compaction on plant growth phosphorus uptake and morphological characteristics of vesicular-arbuscular mycorrhizal colonization of Trifolium subterraneum. New Phytol., 135: 303-311.

Newman, L.A. and C.M. Reynolds, 2005. Bacteria and phytoremediation: new uses for endophytic bacteria in plants. Trends Biotechnol., 23: 6-8.

Pawlowska, T.E. and I. Charvat, 2004. Heavy-metal stress and developmental patterns of Arbuscular mycorrhizal fungi. Applied Environ. Microbiol., 70: 6643-6649.

Paz-Ferreiro, J., H. Lu, S. Fu, A. Mendez and G. Gasco, 2014. Use of phytoremediation and biochar to remediate heavy metal polluted soils: A review. Solid Earth, 5: 65-75.

Pilon-Smits, E., 2005. Phytoremediation. Annu. Rev. Plant Biol., 56: 15-39.

Qian, J.H., A. Zayed, Y.L. Zhu, M. Yu and N. Terry, 1999. Phytoaccumulation of trace elements by wetland plants: III. Uptake and accumulation of ten trace elements by twelve plant species. J. Environ. Qual., 28: 1448-1455.

Rabie, G.H., 2005. Role of arbuscular mycorrhizal fungi in phytoremediation of soil rhizosphere spiked with poly aromatic hydrocarbons. Mycobiology, 33: 41-50.

Roos, P. and I. Jakobsen, 2008. Arbuscular mycorrhiza reduces phytoextraction of uranium, thorium and other elements from phosphate rock. J. Environ. Radioact., 99: 811-819.

Shabani, L., M.R. Sabzalian and S.M. Pour, 2016. Arbuscular mycorrhiza affects nickel translocation and expression of ABC transporter and metallothionein genes in Festuca arundinacea. Mycorrhiza, 26: 67-76.

Shalaby, A.M., 2003. Responses of arbuscular mycorrhizal fungal spores isolated from heavy metal-polluted and unpolluted soil to $\mathrm{Zn}, \mathrm{Cd}, \mathrm{Pb}$ and their interactions in vitro. Pak. J. Biol. Sci., 6: 1416-1422.

Shetty, K.G., B.A.D. Hetrick, D.A.H. Figge and A.P. Schwab, 1994. Effects of mycorrhizae and other soil microbes on revegetation of heavy metal contaminated mine spoil. Environ. Pollut., 86: 181-188.

Sieverding, E., 1990. Ecology of VAM fungi in tropical agrosystems. Agric. Ecosyst. Environ., 29: 369-390.

Smith, S.E. and D.J. Read, 1997. Mycorrhizal Symbiosis. 2nd Edn., Academic Press, London, UK., ISBN-13: 978-0-12-652840-4, Pages: 605.
Sobolev, D. and M. Begonia, 2008. Effects of heavy metal contamination upon soil microbes: Lead-induced changes in general and denitrifying microbial communities as evidenced by molecular markers. Int. J. Environ. Res. Public Health, 5: 450-456.

Tabrizi, L., S. Mohammadi, M. Delshad and B. Moteshare Zadeh, 2015. Effect of arbuscular mycorrhizal fungi on yield and phytoremediation performance of pot marigold (Calendula officinalis L.) under heavy metals stress. Int. J. Phytoremediation, 17: 1244-1252.

Thewys, T., N. Witters, E. Meers and J. Vangronsveld, 2010. Economic viability of phytoremediation of a cadmium contaminated agricultural area using energy maize. Part II: Economics of anaerobic digestion of metal contaminated maize in Belgium. Int. J. Phytoremediation, 12: 663-679.

Tobin, J.M., D.G. Cooper and R.J. Neufeld, 1984. Uptake of metal ions by Rhizopus arrhizus biomass. Applied Environ. Microbiol., 47: 821-824.

Tonin, C., P. Vandenkoornhuyse, E.J. Loner, I. Straczek and C. Leyval, 2001. Assessment of arbuscular mycorrhizal fungi diversity in the rhizosphere of Viola calaminaria and effect of these fungi on heavy metal uptake by clover. Mycorrhiza, 10: 161-168.

Turnau, K., E. Orlowska, P. Ryszka, S. Zubek, T. Anielska, S. Gawronski and A. Jurkiewicz, 2006. Role of Mycorrhizal Fungi in Phytoremediation and Toxicity Monitoring of Heavy Metal Rich Industrial Wastes in Southern Poland. In: Soil and Water Pollution Monitoring, Protection and Remediation, Twardowska, I., H. Allen, M. Haggblom and S. Stefaniak (Eds.). Springer, New York, USA., ISBN: 978-1-4020-4726-8, pp: 533-551.

Usman, A.R.A. and H.M. Mohamed, 2009. Effect of microbial inoculation and EDTA on the uptake and translocation of heavy metal by corn and sunflower. Chemosphere, 76: 893-899.

Wong, C.S.C., X.D. Li, G. Zhang, S.H. Qi and X.Z. Peng, 2003. Atmospheric deposition of heavy metals in the Pearl River Delta, China. Atmosp. Environ., 37: 767-776.

Wang, F.Y., X.G. Lin and R. Yin, 2005. [Influence of arbuscular Mycorrhizal fungi on growth and $\mathrm{cu}$ uptake of Elsholtzia splendens]. Huan Jing Ke Xue, 26: 174-180, (In Chinese).

Wang, F.Y., X.G. Lin and R. Yin, 2007. Role of microbial inoculation and chitosan in phytoextraction of $\mathrm{Cu}, \mathrm{Zn}, \mathrm{Pb}$ and $\mathrm{Cd}$ by Elsholtzia splendens-a field case. Environ. Pollut., 147: 248-255. 